\title{
Distribution and socio-ecological impacts of the invasive alien cactus Opuntia stricta in eastern Africa
}

\author{
Ross T. Shackleton • Arne B. R. Witt - Francis M. Piroris • Brian W. van Wilgen
}

Received: 29 November 2016/ Accepted: 7 May 2017/Published online: 13 May 2017

(C) The Author(s) 2017. This article is an open access publication

\begin{abstract}
Many cactus species have been introduced around the world and have subsequently become major invaders, inducing social and ecological costs. We recorded the distribution of Opuntia stricta in eastern Africa, and conducted 200 household interviews using semi-structured questionnaires to assess local perceptions of $O$. stricta in Laikipia County, Kenya. Opuntia stricta was widespread and abundant in parts of Kenya, Tanzania and Ethiopia and present at low densities in Uganda. In Laikipia County, pastoralists identified that $O$. stricta had been present for more than 10 years, and were of the opinion that it was still spreading and increasing in density. Twothirds of respondents estimated that $50-75 \%$ of valuable grazing land had been invaded, and all felt that it contributed to the ill-health and death of
\end{abstract}

R. T. Shackleton · B. W. van Wilgen

Centre for Invasion Biology, Department of Botany and

Zoology, Stellenbosch University, Matieland 7602,

South Africa

e-mail: rtshackleton@gmail.com

B. W. van Wilgen

e-mail: bvanwilgen@sun.ac.za

A. B. R. Witt ( $\square)$

CABI Africa, PO Box 633-00621, Nairobi, Kenya

e-mail: a.witt@cabi.org

F. M. Piroris

KMA Centre (6th Floor), Mara Road, Upperhill,

PO Box 7055-00100, Nairobi, Kenya

e-mail: imerinyi@gmail.com livestock. Other negative impacts included reductions in native plant populations, rangeland condition, human health, and mobility of humans and animals. These negative impacts resulted in economic losses of US\$ 500-1000 per household per year for $48 \%$ of households. Only $20 \%$ of respondents reported actively managing $O$. stricta, yet all respondents believed a reduction in the abundance of this weed would improve well-being. Management interventions are needed to reduce negative impacts.

Keywords Biological invasions - Distribution mapping · Grazing · Human well-being · Livelihoods · Local ecological knowledge

\section{Introduction}

General introduction

Thousands of plant species have been introduced to countries around the world, both accidentally and intentionally for a host of reasons, including agriculture, forestry, and ornamental purposes (Mack 2003). Subsequently, many of these alien species have naturalised and some have become invasive (Blackburn et al. 2011). For example, it is estimated that there are over 751 invasive trees and shrub species globally (Rejmánek and Richardson 2013). These biological invasions are a major component of global change, 
and they cause numerous negative impacts on biodiversity, ecosystem services, and human well-being (Pimentel 2002; Simberloff et al. 2013). This makes their management important, especially when they also impact on livelihoods. However, it is often difficult to justify the expenditure of scarce resources to support the control of invasive alien species because of a lack of evidence of impacts, or in many cases differences of opinion regarding the magnitude of impacts (Shackleton et al. 2014). When impacts are studied, it is most often from ecological or economic perspectives and studies based on social perspectives are rare, although they are receiving increasing attention (Shackleton et al. 2007; Garcia et al. 2008; García-Llorente et al. 2011; Kull et al. 2011; Kannan et al. 2014; Shackleton et al. 2015). An understanding of social perspectives is important, as it is often people that influence plant distribution and need management of invasions to reduce impacts and enhance benefits. The impact of invasive alien species can often be reliably gauged through an assessment of local knowledge (Chalmers and Fabricius 2007; Sundaram et al. 2012). Such assessments can be particularly valuable in areas where information on impacts is virtually absent, for example in Africa and Southeast Asia (Nuñez and Pauchard 2009). This information can be used to help justify further research in datascarce areas as well as aid in receiving much-needed management funding.

\section{Opuntia stricta}

The Cactaceae is a large family with 130 genera and 1922 species with the majority native to North, Central and South America (Novoa et al. 2015). Numerous cactus species have been introduced around the world for different reasons, including as ornamental plants and to provide fodder and edible products. Of these species, 57 have become naturalised and problematic globally, particularly in arid rangelands (Novoa et al. 2015). Invasive cactus species impact negatively on biodiversity and a range of economic sectors (Novoa et al. 2015), but many species also provide benefits such as revenue through horticulture and provide food, medicinal products and fodder (Einkamerer et al. 2009; Shackleton et al. 2011; Novoa et al. 2016). The situation is often not static, as the costs of invasive species increase and eventually outweigh the benefits as they spread and increase in density (Shackleton et al. 2007; van Wilgen and Richardson 2014). Various invasive cactus species have negative impacts on people, wildlife and livestock movement, reduce the value of grazing land, and negatively impact livestock health and ecological processes (Ueckert et al. 1990; Taylor and Whitson 1999; Novoa et al. 2015), creating a need for active management in order to reduce the negative impacts.

The cactus genus Opuntia contains a high number of problematic species that invade the arid and semi-arid lands of the world-including Opuntia stricta (Haw.) Haw. (known variously as erect or sour prickly pear, or Australian pest pear) (Novoa et al. 2015). Opuntia stricta is a spiny perennial succulent shrub with elongated blue-green cladodes and red-purple fruits which is native to south-east USA, eastern Mexico and some Caribbean Islands. This species has been recorded as naturalised and/or invasive in several African countries, India and Sri Lanka in Asia, Yemen and Saudi Arabia in the Middle East, France, Italy and Spain in Europe, and on the Galápagos islands, Cuba, Madagascar and Australia (CABI 2016). Opuntia stricta was initially introduced to many regions for ornamental and hedging (live fencing) purposes (Foxcroft et al. 2008), but has escaped cultivation and has spread, including into conservation areas (Vilá et al. 2003; Foxcroft et al. 2004), rangelands (Strum et al. 2015) and agricultural areas (Vilá and Gimeno 2003), where it is responsible for a range of negative impacts that have not been systematically quantified (CABI 2016). In Madagascar, invasive $O$. stricta was rated as having no benefits in comparison to other Opuntia species as the fruit were seen as inferior and cladodes were not used as fodder (Larsson 2004). Furthermore, $O$. stricta was seen as the most problematic invasive Opuntia species on the island, causing problems such as reduced fodder production, impeding mobility and impacting livestock and human health (Larsson 2004).

In the study reported here, we surveyed the broadscale distribution and extent of invasions of $O$. stricta in eastern Africa, and gauged local perceptions of the value, impact and management of this species in the context of rural pastoralists in Africa. We then used our findings to make recommendations for management of this species in the region. 


\section{Methods}

Study site

The study took place at two spatial scales. One was at a broad regional scale and included a survey of the distribution and abundance of $O$. stricta in parts of Kenya, Rwanda, Tanzania, Uganda and Ethiopia (Fig. 1). The second was an assessment of the distribution of $O$. stricta at a local level, in Laikipia County, Kenya (Fig. 2).

The livelihood impact survey was conducted in the small town of Dol Dol and neigbouring villages $\left(0.393884^{\circ} \mathrm{S}: 37.164296^{\circ} \mathrm{E}\right)$ in the northeast of Laikipia County, central Kenya, where O. stricta is common on communal land (Fig. 2). Surveys were conducted in this area because it is considered to be the

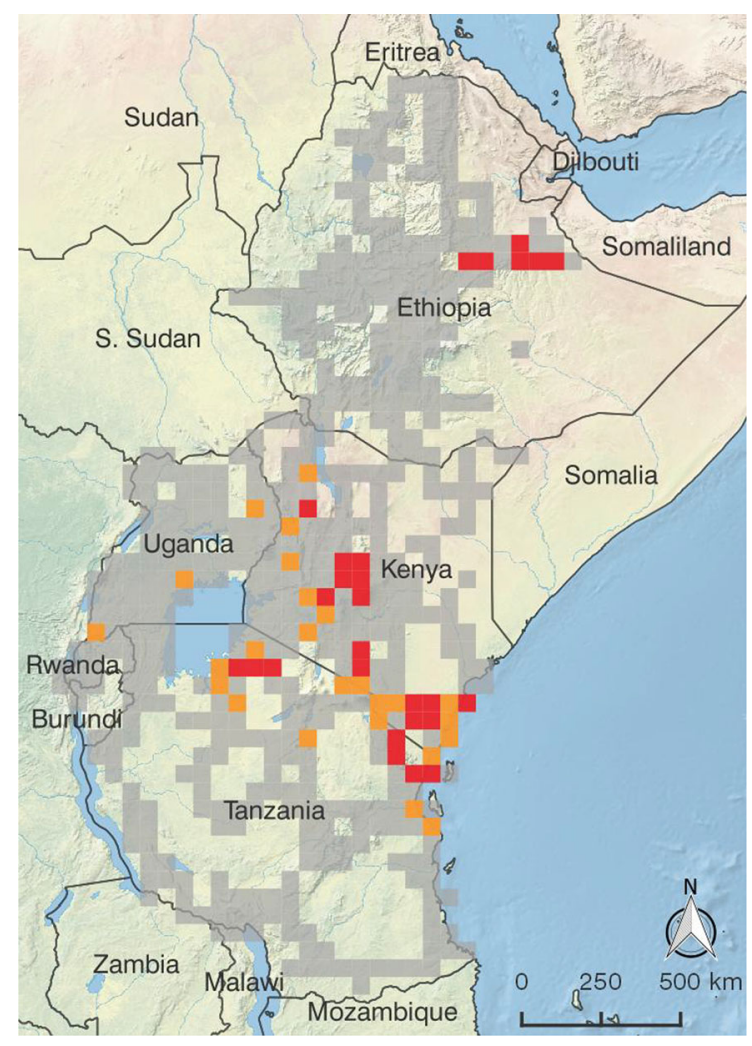

Fig. 1 The distribution of Opuntia stricta (both varieties) in eastern Africa (Ethiopia, Kenya, Rwanda, Tanzania and Uganda), shown in $1 / 2$ degree grid cells $(\sim 55 \times 55 \mathrm{~km})$. Grey grid cells represent surveyed areas where no $O$. stricta was seen $(\mathrm{n}=1011 ; 95 \%)$, orange where it was present or naturalized $(\mathrm{n}=25 ; 2.43 \%)$, and red where it was invasive (widespread or localized and abundant) $(\mathrm{n}=27 ; 2.57 \%)$ source of current $O$. stricta invasions. Dol Dol also has relatively high human population levels compared to the rest of the invaded area, making it easier to undertake socio-economic surveys. This area has a temperate climate with mean annual rainfall of between 200 and $600 \mathrm{~mm}$ and mean annual temperatures of $16-26{ }^{\circ} \mathrm{C}$. Laikipia County lies at the meeting point of the Somalia-Maasai Bushland and the Afromontane-Afroalpine biotic zones represented by grasslands, bushland, woodland and dry forests (Butyanski and de Jong 2015). The vegetation of the survey area is a mixture of grasslands and savannas, where the most common native trees are those in the genera Vachellia (formerly Acacia) and Commiphora.

Communities residing in the communal rangelands of Laikipia County are mainly Mukogodo Maasai pastoralists who have recently adopted a semi-sedentary lifestyle. Areas of settlement are relatively underdeveloped, with most households relying on livestock (for meat and milk, or sale), and natural resources for sustenance. The human development index, which is a combined statistic of life expectancy, education, and per capita income indicators, for the region is low (0.412) and is less than the national average (0.561) (Government of Kenya 2013). This suggests that the communities in the study site would be vulnerable to any further degradation of the environment on which they depend. Dol Dol and the surrounding areas have a population density of 12 people $/ \mathrm{km}^{2}$, which is lower than the 42 people $/ \mathrm{km}^{2}$ found in other areas within Laikipia County (Kenya National Bureau of Statistics 2010). The economy of the County is largely driven by tourism (private wildlife ranches/conservancies) and rangeland grazing on communal lands (Government of Kenya 2013). Both of these land tenure systems rely heavily on large and intact rangelands.

Data collection

\section{Mapping of O. stricta}

Information on the presence and status of $O$. stricta was recorded during roadside surveys in Kenya, Tanzania, Uganda, Rwanda and Ethiopia. These surveys took place between 2008 and 2015, and covered tens of thousands of kilometres. Similar roadside surveys have been undertaken in Angola and South Africa and are a cost-effective way of getting a broad scale understanding of the extent of 


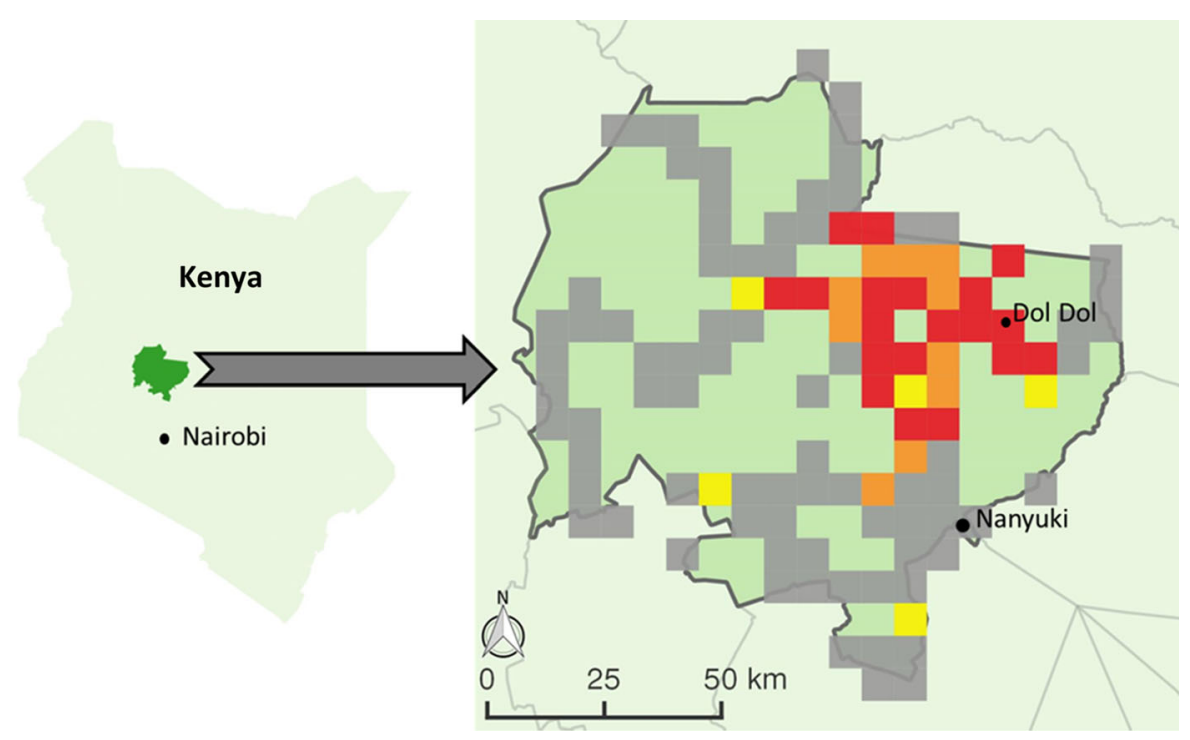

Fig. 2 Kenya, showing the locality of Laikipia County (left), and the distribution of $O$. stricta var stricta in Laikipia, as determined by surveys undertaken from 2013 to 2015, represented in $1 / 16$ of a degree grid cells $(\sim 11 \times 11 \mathrm{~km})$ (right). Grey grid cells represent surveyed areas where no $O$.

invasions and have been a key data source for aiding research and management in the country as well as guiding further detailed mapping (Henderson 2007; Rejmánek et al. 2016). We recorded the GPS coordinates of sites where $O$. stricta occurred, and noted it's status in terms of the categories proposed by Blackburn et al. (2011) (present/casual, naturalized or invasive). As there are two varieties or sub-species of $O$. stricta in eastern Africa, we also noted the variety present (either $O$. stricta var. stricta or $O$. stricta var. dillenii). Opuntia stricta var. dillenii has 4-7, and sometimes up to 11 spines per areole, while var. stricta has 0-1 spines per areole (Parfitt and Gibson 2003). Isolated individual plants, across a wider landscape, were considered to be present or casual while naturalized plants were considered to be those that had established self-perpetuating populations, but which were not yet widespread and abundant or localized and abundant (invasive) in the areas where they were found. The distribution and abundance of $O$. stricta within eastern Africa was mapped at 1/2-degree grid cells $(\sim 55 \times 55 \mathrm{~km})$, by recording in which grid cells the species was present and/or naturalized or invasive (see Fig. 1). Distributions within Laikipia County, Kenya, were mapped at a higher resolution $(\sim 7 \times 7 \mathrm{~km})$, showing where 0 . stricta was present stricta was seen $(\mathrm{n}=75 ; 69 \%)$, yellow where it was present but rare $(\mathrm{n}=5 ; 5 \%)$, orange where it was naturalized $(\mathrm{n}=10$; $9 \%$ ), and red where it was invasive (widespread or localized and abundant) $(\mathrm{n}=19 ; 17 \%)$

but not naturalized or invasive (yellow), naturalized (orange) or invasive (red) (see Fig. 2). It should be noted that in most cases only a part of each grid cell could be surveyed, and as such the distribution maps are merely an approximation of the presence and density of $O$. stricta.

\section{Livelihoods survey}

Information on local knowledge and perceptions of $O$. stricta was collected using semi-structured questionnaires in which 200 respondents were interviewed at their households in late 2014. This technique (eliciting local ecological knowledge) is growing in the field of invasion biology, as it is a cost-effective way of providing a useful understanding of how invasive species impact on humans (García-Llorente et al. 2011; Shackleton et al. 2015). The questionnaire surveys were conducted in Dol Dol and 20 villages in Laikipia County where the extent of invasion by $O$. stricta on communal land varied from moderate to high (Fig. 2). Households were randomly selected, and the head of the household (or a suitable alternative if the head was not present) was interviewed in their local language (Maasai or Swahili) by a local field assistant. The questionnaires consisted of mainly 
close-ended, listing and ranking questions, but also some open-ended questions with four key sections. These sections included: (1) demographics of the household; (2) understanding and perceptions of the introduction and spread of $O$. stricta; (3) understanding and perceptions about the benefits and costs of $O$. stricta and; (4) questions relating to management practices. Values are reported in US\$ based on a current (2016) exchange rate of approximately 100 KSH (Kenyan Shillings) to one US\$ (US Dollars).

Data analysis

Data mining techniques (Principle Component and Cluster analysis) were used to assess broad scale relationships between the demographic variables of the participants and their responses. However, these revealed no significant relationships or clustering. We then ran Chi square analysis for categorical variables, independent $T$ tests (Mann-Whitney $\mathrm{U}$ tests if assumptions not upheld), one-way ANOVA and Games Howell post hoc tests, and linear regressions for continuous and ordinal data. We ran these analyses using the demographic data (gender, employment, age, education level and number of livestock) as independent variables, and the questionnaire responses as dependent variables. We only report on those relationships that were found to be significant.

\section{Results}

Distribution of O. stricta in eastern Africa

Opuntia stricta was found to be present in Ethiopia, Kenya, Tanzania, and Uganda but was not found in Rwanda (Fig. 1; Table 1). Opuntia stricta var. stricta was found to be widespread and abundant in eastern Ethiopia, especially between and around Alemaya and Jijiga, where it was often found to be growing in semiarid rangelands and on rocky outcrops in association with $O$. ficus-indica (L.) Mill (sweet prickly pear). In Kenya, O. stricta var. stricta was found to be abundant in Laikipia County and Tsavo East National Park. It is assumed that $O$. stricta var. stricta infestations originated in the town of Dol Dol in Laikipia County, where it is now present, naturalized or invasive on 34 (31\%) of the $110(48 \%) \quad 1 / 16$ degree grid cells surveyed in the County itself. It is abundant on overgrazed communal rangelands and some of the adjoining conservancies, which are well managed and not overgrazed. We estimate that this variety has also invaded about $500 \mathrm{~km}^{2}$ of Tsavo East National Park and assume that it is also present on adjoining rangelands. Insecurity and poor road access, in both East Africa and Ethiopia, prevented detailed surveys from being undertaken in some areas, so cactus distributions are possibly an underestimate, but are an important baseline to guide future surveys and management strategies.

Opuntia stricta var. dillenii was also present along the Kenyan coastline where it has escaped from hedge plantings. More recently a small infestation was found near Lake Baringo, growing amongst metamorphic and volcanic rocks, in association with $O$. elatior Mill. (red-flower prickly pear) and Prosopis juliflora (Sw.) DC. (Fabaceae; mesquite). This variety is widespread and abundant in parts of the Serengeti District, Tanzania, especially near Ikoma and Robanda, on the edge of Grumeti Game Reserve and Serengeti National Park with some isolated stands further to the west. There are smaller infestations in dry savanna to the south of Mount Kilimanjaro and along the Tanzanian coast. It is present, but at low densities, in parts of Uganda where it has escaped from planted hedges.

Demographic data of respondents in Laikipia County

The majority (65\%) of the 200 interview respondents were male. The mean $( \pm \mathrm{SD})$ age of the respondents was $39 \pm 13$ (min. -19 ; max. -72) years, living in households with a mean of $7 \pm 5$ (min. -1 ; max. -17 ) people. The majority of respondents had no formal schooling (59\%) with $21 \%$ having only primary schooling. Most respondents were pastoralists (36\%), followed by housewives or those having no formal employment (33\%), with $18 \%$ working as unskilled labour and the remainder (13\%) working skilled jobs or owning small businesses. The skilled jobs included rangers, teachers and social workers. Almost all households had livestock (99\%) with a mean $( \pm \mathrm{SD})$ of $32 \pm 44$ (min. -0 ; max. -300$)$ goats, $33 \pm 48$ (min. -0 ; max. -300 ) sheep and $10 \pm 14$ (min. -0 ; max. -78 ) cattle with $77 \%$ of respondents grazing their livestock between 1 and $5 \mathrm{~km}$ away from their homesteads. Male-headed households had 
Table 1 The percentage of grid cells (approximately $55 \times 55 \mathrm{~km}$ ) in each of the four African countries surveyed from 2008 to 2015 , together with the percentage of those grid cells in which $O$. stricta was found to be naturalized or invasive

\begin{tabular}{|c|c|c|c|c|}
\hline \multirow[t]{2}{*}{ Country } & \multirow[t]{2}{*}{ O. stricta variety } & \multicolumn{3}{|c|}{$\%$ grid cells } \\
\hline & & Surveyed & $\begin{array}{l}\text { Present or } \\
\text { naturalized }\end{array}$ & Invasive \\
\hline Ethiopia & O. stricta var. stricta & 37 & - & 4.5 \\
\hline \multirow[t]{2}{*}{ Kenya } & O. stricta var. stricta & 65.2 & 10 & 10 \\
\hline & O. stricta var. dillenii & - & 2.3 & 0.8 \\
\hline Tanzania & O. stricta var. dillenii & 49.1 & 6.5 & 4 \\
\hline \multirow[t]{2}{*}{ Uganda } & O. stricta var. stricta & 74.4 & 3 & - \\
\hline & O. stricta var. dillenii & - & 1.5 & - \\
\hline
\end{tabular}

significantly more cattle (Mann-Whitney U: $\mathrm{F}=15.85 ; p<0.01)$ than female-headed households. Education level, having a job, and a large number of cattle were highly correlated (indicator of poverty/ wealth). For example, households with tertiary and secondary education had significantly more cattle (mean of 152 and 118 cattle respectively) than households with primary and no education (mean of 76 and 73 cattle respectively) $(\mathrm{F}=4.52 ; p=0.01)$.

Introduction and spread of Opuntia stricta in Laikipia County

Invasions of $O$. stricta are perceived to be widespread and increasing in many different environments in the Dol Dol area. All respondents (100\%) mentioned that $O$. stricta was present on the land where they grazed their livestock (Fig. 3). The majority of respondents indicated that $O$. stricta had been in the area for more than 10 years (Fig. 4). Significantly more men than women did not know in which time period $O$. stricta first appeared in the area $\left(\chi^{2}=8.53(d f=1)\right.$; $p<0.03$ ); furthermore less educated respondents were better at giving an approximate period of arrival than better educated respondents $\left(\chi^{2}=8.64(d f=3)\right.$; $p=0.034)$. Two-thirds of respondents $(67 \%)$ estimated that $O$. stricta covered $50-75 \%$ of their grazing land, while $20 \%$ thought it was less widespread, and $10 \%$ thought it was more widespread (Fig. 5). All respondents $(100 \%)$ thought that $O$. stricta invasions were increasing in their area. More than $25 \%$ of people identified that the three primary areas that $O$. stricta invades are near rivers, homes and on hills/mountains (which are the most valuable grazing areas), while
$14 \%$ mentioned it as being common on rocky outcrops (Figs. 3, 6).

Perceptions of the reasons for the introduction of $O$. stricta differed between respondents. The majority of respondents (74\%) did not know why $O$. stricta was originally introduced. Others believed it was introduced either as a hedge $(11 \%)$ or as a garden plant $(8 \%)$, to combat erosion (5\%), with very few $(3 \%)$ believing that it was introduced for food and fodder. Older respondents knew the reason for introduction, unlike many of the younger respondents (MannWhitney $\mathrm{U}: \mathrm{F}=4.457 ; p=0.05$ ). One respondent (mistakenly) believed it was introduced by researchers to feed baboons as part of a scientific experiment. People did, however, have a better knowledge on the vectors of spread in the local area. Most respondents $(>25 \%)$ believed it to be spread by wildlife (primarily baboons) or livestock, or that it spread naturally on its own, with fewer (14\%) mentioning that it was spread by people (Figs. 3, 7).

\section{Benefits of Opuntia stricta}

According to residents, O. stricta did not provide much in the way of benefits (Table 2). A fifth (20\%) of respondents reported eating $O$. stricta fruit, with the remaining $80 \%$ saying they ate it only rarely or never. Significantly, more men reported eating $O$. stricta than women $\left(\chi^{2}=4.02(d f=1) ; p=0.044\right)$ as they are likely to spend more time in the rangelands herding their livestock (Tangka et al. 2000). Respondents mentioned that a lot of time and effort is needed to remove the small barbs (glochids) from the fruit and that it could only be eaten in moderation otherwise it 

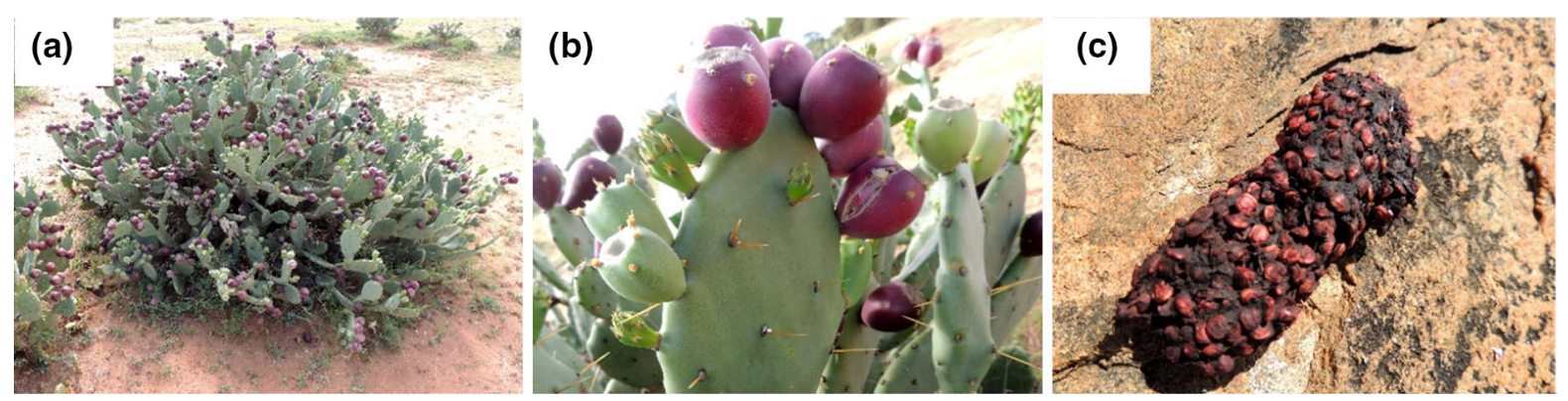

(d)
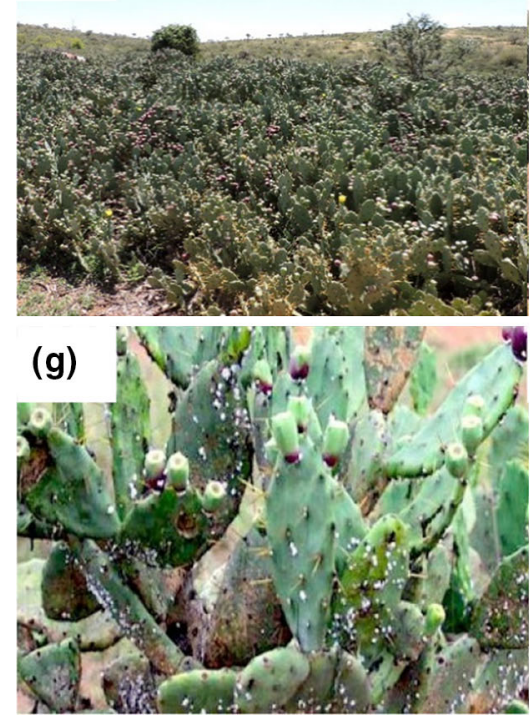

(e)

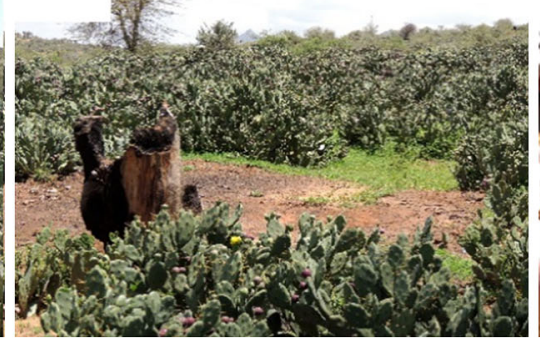

(h)

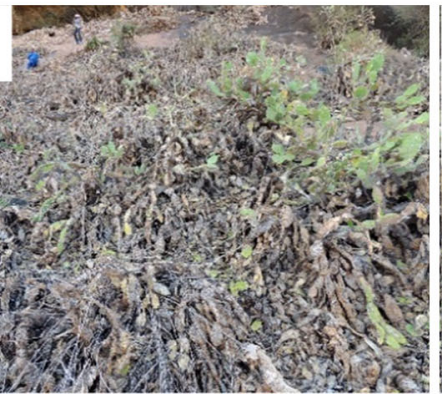

(f)
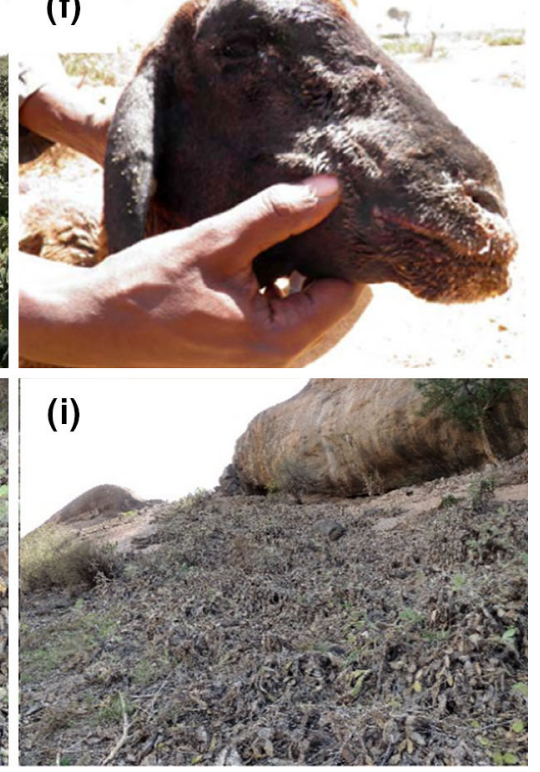

Fig. 3 a Opuntia stricta plant; b $O$. stricta close-up showing fruit (glochids on fruit), and spines; $\mathbf{c}$ baboon scat full of $O$. stricta seeds; d, e $O$. stricta invasions in rangelands; $\mathbf{f}$ sheep blinded by

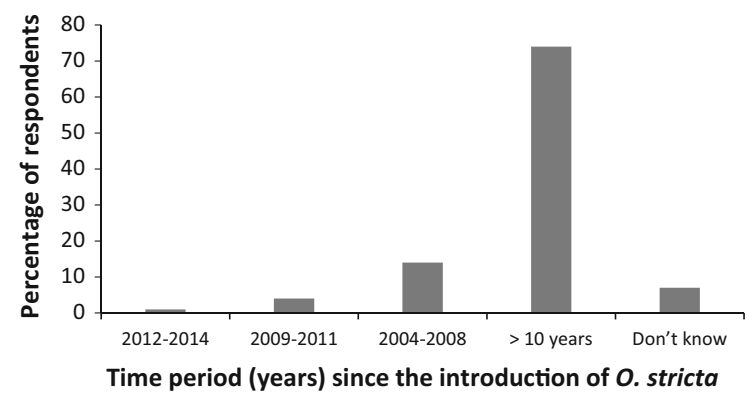

Fig. 4 Respondents views on the date of arrival of $O$. stricta var stricta in their area in Laikipia County, Kenya, as determined by a socio-ecological survey undertaken in $2014(\mathrm{n}=200)$

would result in stomach 'irritation' (see below). In addition, $50 \%$ of respondents mentioned that $O$. stricta increased the presence of other trees and shrubs, because invaded areas protect native seedlings and cactus spines; g Dactylopius opuntiae (cochineal) biological control agent on $O$. stricta; and $\mathbf{h}, \mathbf{i}$ impacts of D. opuntiae on $O$. stricta in Laikipia County, Kenya (photos by ABRW)

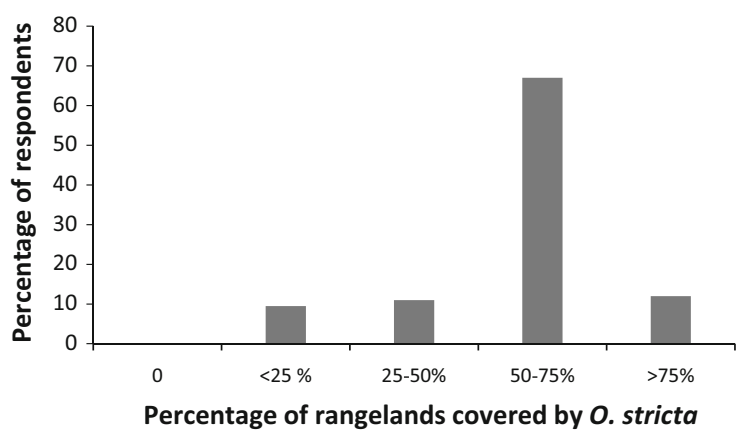

Fig. 5 Respondents ranking on the cover of O. stricta var stricta on rangelands in the Dol Dol area, Laikipia County, Kenya, as determined by a socio-ecological survey undertaken in $2014(\mathrm{n}=200)$

saplings from livestock browsing. This is not uncommon, and is known as "associational resistance", whereby spiny or unpalatable plant species effectively 


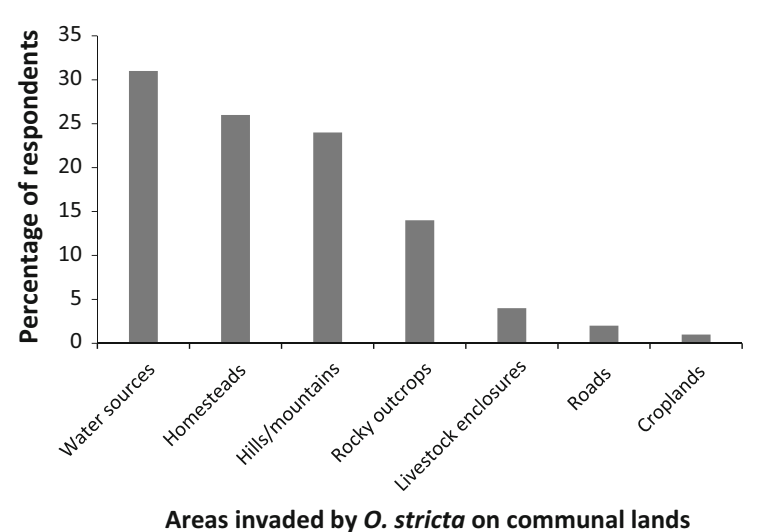

Fig. 6 Respondents ranking of general areas where O. stricta var stricta is most invasive within rangelands in the Dol Dol area, Laikipia County, Kenya, as determined by a socioecological survey undertaken in $2014(\mathrm{n}=200)$

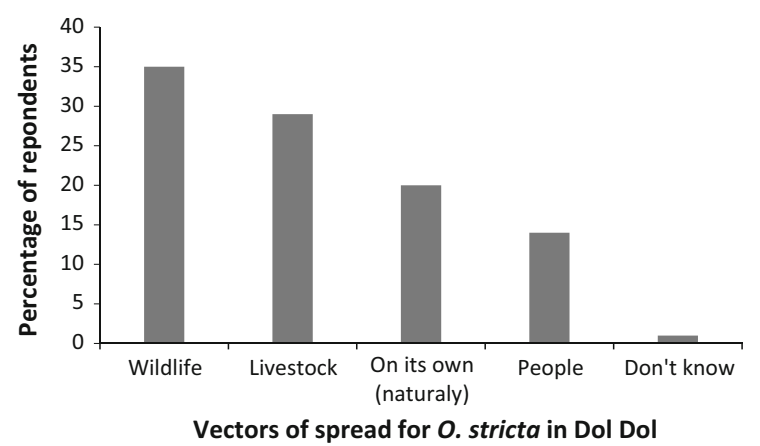

Fig. 7 Respondents views on the main vectors of spread of $O$. stricta var stricta within rangelands in the Dol Dol area, Laikipia County, Kenya, as determined by a socio-ecological survey undertaken in $2014(\mathrm{n}=200)$

Table 2 Perceptions of households regarding the net impacts and benefits of $O$. stricta invasion on a range of environmental measures. Invasions may not have a direct negative impact on protect other plant species from browsing animals (Smit et al. 2005, 2006). According to Smit et al. (2007) an "extremely toxic and well-defended nurse plant" would provide significant protection to associated recruits.

\section{Costs of Opuntia stricta}

The majority of local people were of the opinion that $O$. stricta invasions resulted in net negative impacts by degrading rangelands, reducing the benefits gained from livestock production, and impacting on their own health (Table 2). All respondents (100\%) mentioned that $O$. stricta infestations had a negative impact on livestock health. The major negative impacts on livestock included blindness caused by $O$. stricta spines piercing their eyes, especially during dry periods when little other forage is available, and livestock try to access grass and small shrubs growing near or in cactus stands (Fig. 3; Table 3). Consumption of fruit resulted in the lodging of glochids in the lips, mouths and gastro-intestinal tracts of animals, leading to weight loss and a reduction in milk production, often followed by death (Fig. 3; Table 3). In addition, many respondents mentioned that if livestock eat $O$. stricta fruit there is a reduction in tripe quality and value (Tables 2, 3). People mentioned that the intestinal lining of slaughtered livestock were full of glochids, which often resulted in the formation of yellow pustules. The majority of people

grasses and other plants, but may prevent access to these resources. Data are expressed as a percentage of all households $(\mathrm{n}=200)$

\begin{tabular}{lccc}
\hline Effects of $O$. stricta & Negative impacts & Positive benefits & No effect/don't know \\
\hline Tripe quality & 100 & 0 & 0 \\
Livestock health & 100 & 0 & 0 \\
Movement/access & 96 & 0 & 4 \\
Grass & 91 & 6 & 3 \\
Wildlife & 91 & 0 & 9 \\
Human health & 84 & 0 & 16 \\
Useful plants & 43 & 0 & 57 \\
Shrubs & 30 & 50 & 20 \\
Trees & 19 & 50 & 31 \\
Water & 8 & 0 & 92 \\
Fruit consumption by humans & 0 & 20 & 80
\end{tabular}


Table 3 Negative impacts of $O$. stricta invasions on livestock in Laikipia County, Kenya

\begin{tabular}{ll}
\hline Negative impact on livestock & $\begin{array}{l}\text { Percentage of } \\
\text { respondents (those } \\
\text { mentioned by 10\% } \\
\text { and above) }\end{array}$ \\
\hline Mouth sores & 87 \\
Weight loss & 83 \\
General sickness & 74 \\
Less milk & 63 \\
Blindness/eye injury & 58 \\
Death & 54 \\
Impacts on gastrointestinal tract & 52 \\
Swollen, hardened and sore lips & 46 \\
Thorns in body & 39 \\
Fewer offspring & 12 \\
\hline
\end{tabular}

(90\%) said they could no longer sell tripe (a delicacy, especially for Maasai women).

Opuntia stricta was also seen by many respondents as reducing the value of livestock by causing illness leading to poor condition. Another key negative impact of $O$. stricta invasion, mentioned by $96 \%$ of respondents, was the fact that invasions hinder human and livestock movement to water sources, homesteads and grazing lands. Numerous negative impacts caused by $O$. stricta were highlighted by $91 \%$ of respondents who mentioned that invasions reduced access to grasses (important for livestock) and impacted negatively on wildlife populations (Table 2). Loss of useful plants, primarily medicinal plants, was mentioned by $43 \%$ of respondents, while $84 \%$ highlighted that invasions impacted negatively on human health by causing eye and skin irritations, probably as a result of coming into contact with the glochids on the fruit. The only significant differences that arose between the demographic variables and responses on costs of $O$. stricta were that women mentioned negative impacts on water availability significantly more than men $\left(\chi^{2}=5.84 ; p=0.015\right)$. This could be ascribed to the fact that in most rural communities women are tasked with collecting water for household use.

Respondents estimated that in the past year they had lost (on average, \pm SD) $9 \pm 11$ (min. -0 ; max. -180 ) goats, $7 \pm 8$ (min. -0 ; $\max$. -250 ) sheep, and $15 \pm 20$ (min. -0 ; max. -120 ) cattle due to the presence of $O$. stricta. This amounts to mean annual

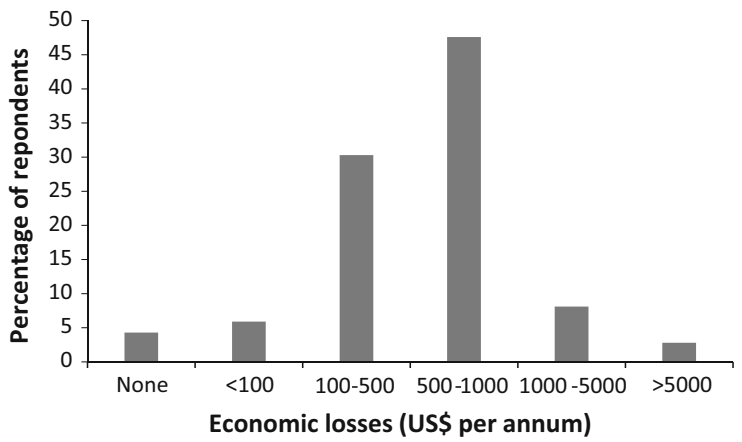

Fig. 8 The estimated economic losses in livestock production among community members in the Dol Dol area, Laikipia County, Kenya, as a result of $O$. stricta var stricta invasions as determined by a socio-ecological survey undertaken in 2014 $(\mathrm{n}=184)$

losses of between US\$ 500-1000 and US\$100-500 per household for 48 and $30 \%$ of the respondents, respectively (Fig. 8).

Costs of Opuntia stricta relative to other socialecological drivers

When asked to select the most important threat to livestock production, the largest proportion of respondents $(35 \%)$ identified weeds and poisonous plants as the most important, followed by insufficient grazing (31\%), which may also be as a result of plant invasions, followed by disease (20\%), livestockwildlife conflict (11\%), with lack of water and stock theft being ranked as very low (Fig. 9a). When asked to identify the most problematic plant species, $O$. stricta was cited as the worst weed in the area (55\%) followed by Austrocylindropuntia subulata (Muehlenpf.) Backeb. (Cactaceae; Colville cactus) (35\%), native Sansevieria spp. (Asparagaceae) and O. ficusindica (L.) Mill., both 5\% (Fig. 9b). This illustrates that people were well aware of the multiple factors that could affect their wellbeing, including how these issues were affected by invasive alien plants.

\section{Management of Opuntia stricta}

Despite the fact that residents recognised that $O$. stricta caused many negative impacts, only $20 \%$ of respondents mentioned that they had attempted to remove or control the spread of $O$. stricta. 


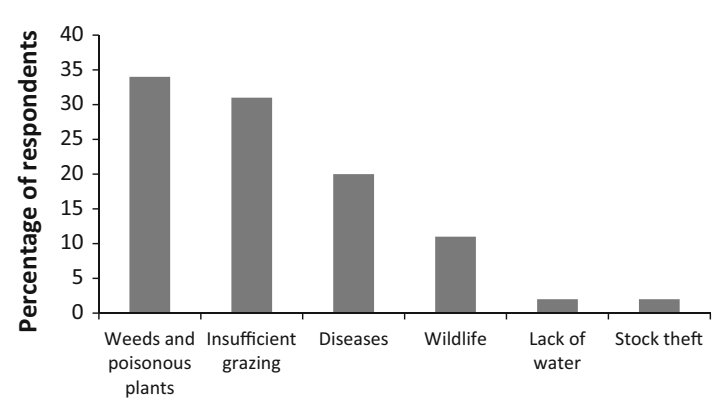

Ranking of impacts on livestock farming in the Dol Dol area

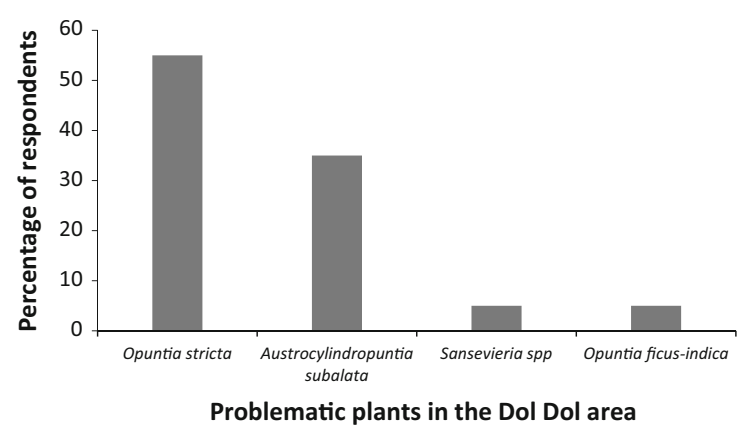

Fig. 9 Ranking of the most prevalent threats to livestock production (top), and the major problematic plants (alien and native) affecting rangelands (bottom) in the Dol Dol area, Laikipia County, Kenya, based on head of household responses during a socio-ecological survey undertaken in $2014(\mathrm{n}=200)$

Significantly more women respondents reported managing $O$. stricta than men $\left(\chi^{2}=4.54(d f=1)\right.$; $p=0.03)$. Of those that did attempt management, $29 \%$ reporting trying to burn the plants, and $98 \%$ reporting using both physical methods (slashing, cutting, digging) and burning. Only $7 \%$ of respondents reported paying people to help to clear infestations and payments were all less than US\$ 100 per ha. The majority of respondents (89\%) had heard of biological control with $88 \%$ of respondents having seen the cochineal (Dactylopius spp.; Dactylopiidae), a sap sucking insect, on Opuntia spp. in the area (Fig. 3). Based on these observations, about a third of respondents (36\%) believed that biological control was safe, with the remainder being unsure of the potential risks or benefits it posed. However, all respondents were happy to endorse and support any cost-effective and safe way of managing $O$. stricta. All respondents $(100 \%)$ also believed that a reduction in O. stricta invasion density would improve grazing land, livestock health and livelihoods, while $99 \%$ were of the opinion that it would increase the value of land.

\section{Discussion}

\section{Distribution and impacts of Opuntia stricta}

This study found that $O$. stricta var. stricta was widespread and abundant in Kenya and in areas in eastern Ethiopia that we were able to survey, with $O$. stricta var. dillenii dominating in Tanzania. Invasions only started becoming prolific in the recent past, based on opinions of landowners and community members, and it is believed that they could potentially spread and increase in density in many areas in eastern Africa. Local people had a good understanding of the reason for introduction (ornamental purposes and hedging), and that wildlife and livestock were the main dispersal agents, as has been demonstrated in the Kruger National Park, South Africa, where baboons (Papio ursinus Kerr; Cercopithecidae) and elephants (Loxodonta africana Blumenbach; Elephantidae) were found to be key dispersers of O. stricta (Foxcroft et al. 2004). Baboons were also identified as one of the main dispersal agents in pastoral rangelands in Kenya (Strum et al. 2015) together with elephants, tortoises and possibly also vulturine guineafowl (Acryllium vulturinum Hardwicke; Numididae) (A.B.R. Witt pers. obs.). Baboons are largely responsible for dispersing cactus seeds to rocky hilltops because that is where they tend to reside at night, a habitat identified by pastoralists as having large and dense infestations. In addition, high cactus densities are likely to occur around water sources and near homesteads, since livestock spend considerably more time in these areas, where they deposit cactus seeds in manure. Crows are a major dispersal agent of invasive Opuntia species across large parts of the arid interior of South Africa (Dean and Milton 2000), and other bird species in Laikipia, such as lark's, sparrows and pipits, were observed eating $O$. stricta seeds, especially in elephant dung (D. Scott pers. obs.), and as such are also likely dispersal agents.

In Madagascar, Larsson (2004) highlighted that unlike other Opuntia species, O. stricta has less benefits and higher impacts which reduce human wellbeing. This is in accordance with our findings which show substantial negative impacts of $O$. stricta for local livelihoods with very few benefits. All villagers were of the opinion that $O$. stricta invasions had a negative impact on ecosystem goods and services, biodiversity and human well-being. In particular loss 
of livestock production and a reduction in animal health were seen to increase vulnerability of pastoralists in Laikipia County, with significant economic losses.

Veterinary studies documenting the livestock health impacts of Opuntia species (Ueckert et al. 1990; Hanselka and Paschal 1991) support the claims made by local pastoralists in this study. The spines and glochids are known to cause irritation, swelling and ulceration of lips, tongues and mouths, an affliction referred to as pear mouth and cactus tongue. The glochids on the fruit, once consumed, also lodge in the gastro-intestinal tract causing irritation, ulcers and pustules, often leading to secondary infections, and death. Excessive consumption of fruit may result in constipation, affecting rumen function, which has also been linked to the loss of livestock (Ueckert et al. 1990; Hanselka and Paschal 1991) and to reduced lactation and often loss of young (Merrill et al. 1980). In a national beef quality audit it was found that $22.5 \%$ of US cattle had cactus tongue, making them unsuitable for market and human consumption (Garcia et al. 2008). Other semi-arid rangeland invasive species such as Prosopis spp. are also known to impact negatively on livestock health, through loss of teeth (due to consumption of the pods which have a high sugar content), and thorn injuries (Shackleton et al. 2015).

Furthermore, O. stricta invasions were perceived by many villagers to reduce native plant occurrence, which negatively impacts livestock production, natural resource collection and biodiversity in the area. In contrast, some pastoralists mentioned that $O$. stricta presence increased the abundance of grasses, shrubs and trees. Opuntia stricta may act as a nurse plant, supporting and protecting native plant species growing within stands from browsing by livestock and wildlife, considerably reducing the carrying capacities of invaded landscapes (Taylor and Whitson 1999). In other words cactus spines, which can cause serious injury to many animal species, prevent them from gaining access to, and feeding on palatable species growing within individual plants and/or cactus stands. The loss of grazing potential due to Opuntia species invasions is supported by other studies (Price et al. 1985). Research in the USA found that around each cactus plant there was a $15-20 \mathrm{~cm}$ wide buffer that was not grazed, which is comparable to twice the area of the cactus plant itself (Taylor and Whitson 1999). If
$20 \%$ of a pasture, which produces $450 \mathrm{~kg}$ of forage, is invaded by cactus, $160 \mathrm{~kg}$ of potentially utilisable forage is lost or inaccessible to livestock (Taylor and Whitson 1999). This amounts to a considerable reduction in carrying capacities based on the premise that one sheep consumes $2.5-3 \%$ of its body weight per day which amounts to approximately $3 \mathrm{~kg}$ of hay or grass daily (Taylor and Whitson 1999). One hundred and sixty kilograms of grass could potentially feed 53 sheep for 1 day. If $50 \%$ of the same pasture, one that produces $450 \mathrm{~kg}$ of forage, was invaded by cactus, forage availability could be reduced by $225 \mathrm{~kg}$, enough to feed 75 sheep for 1 day.

Other than the loss of access to forage and negative impacts on livestock health, local pastoralists mentioned that these invasive cacti also inhibited the movement of people, decreased the availability of natural resources (native plants primarily for medicinal purposes), and had negative impacts on human health. Spines and glochids have been reported in medical journals to cause physical injuries, and can induce allergenic reactions resulting in sarcoma, foreign-body granulomas and ulceration (Barney 1925; Boyd 1955; Schreiber et al. 1971), which supports local claims.

Although this study focused on human livelihoods, $O$. stricta also has negative effects on wildlife, which could impact on ecotourism, a major source of employment for many community members. It is unknown if fruit consumption by wildlife has similar negative impacts as those reported for livestock. Elephants readily consume cactus fruit and are key dispersal agents (Foxcroft et al. 2004). During a drought in Laikipia County in 2009, a large number of young elephants died. Abscesses, similar to those found in livestock, were also observed in the mouths of dead elephants, and the assumption was made that these were caused by glochids from the cactus fruit lodging in their mucosal membranes, an observation supported by many respondents employed as game guards. Whether or not the consumption of cactus fruit contributed to the demise of these animals remains unknown, and further research would be needed to establish whether this observation is valid. The attraction of elephants to the fruit of cacti has also contributed to increased human-wildlife conflict, with elephants encroaching on grazing especially in communal lands, which have extensive cactus infestations. 
Shackleton et al. (2007) proposed a framework that classified invasive alien species in terms of their potential effects on livelihoods. Under this framework, species are placed into one of four possible categories: (1), undesirable but weakly competitive species that have little effect on human well-being (2), undesirable species that are strongly competitive, resulting in large negative impacts on local livelihoods (3), desirable species that are weakly competitive, therefore being primarily beneficial and (4), species that are useful and strongly competitive, and so have both substantial benefits and costs for humans and therefore often have conflicts of interest surrounding them. According to the framework, O. stricta can be categorised as an undesirable strongly competitive weed. This is a species that has few benefits and major costs for community livelihoods. According to the framework, as $O$. stricta spreads and increases in density, there will be an increase in the vulnerability of local communities. This is different from other invasive species such as Australian acacias that can be both beneficial and harmful at the same time (de Wit et al. 2001; Richardson and Rejmánek 2011) and can be categorised as useful strongly competitive invasive species (Shackleton et al. 2007). This suggests that management will be needed to prevent a decline in human well-being, especially for communities that are already vulnerable, since negative impacts are likely to increase. The research here has provided a basis for further study (detailed mapping and field experiments to measure impacts on biodiversity and human and livestock health), and can be used as leverage to encourage governments and other agencies to provide additional funds for research and management.

\section{Management options}

The negative effects of $O$. stricta on human wellbeing, ecosystem services and biodiversity highlights the need to manage these invasions. Various control options exist for $O$. stricta which need to be integrated and coordinated for maximum effect, especially in conservation areas as has been done in the Kruger National Park (KNP), South Africa (Lotter and Hoffmann 1998; Foxcroft and Richardson 2003). This includes the integration of various control options such as physical, chemical and biological control which should be implemented in conjunction with other activities, including awareness creation and capacity development. In the Dol Dol area (and we suspect for the rest of eastern Africa) there is currently little control, and that which is being undertaken focusses mainly on physical removal and burning which is time-consuming, expensive and largely ineffective, especially if all the roots and/or cladodes are not removed (Lotter and Hoffmann 1998). Opuntia stricta can reproduce vegetatively, making physical control difficult, as any piece of the plant left on the soil surface will regenerate. Herbicide application is more effective and monosodiummethylarsenate (MSMA) can be injected onto large plants or sprayed onto small plants and loose cladodes (Lotter and Hoffmann 1998). However, this herbicide can be costly and can be damaging to other plants so care needs to be taken in its use. More recently, glyphosate has been suggested as a safer alternative however, the waxy layer on the cladodes means that high concentrations need to be applied which increases costs. Triclopyr based herbicides are also widely used. Larsson (2004) reports that no community in Madagascar was able to effectively control $O$. stricta invasions using manual methods, making the provision of herbicides to aid control important in the future.

Biological control is often considered as the most cost-effective and successful method of control for many invasive species (Moran et al. 2005; Page and Lacey 2006; van Wilgen et al. 2012) and the same has been suggested for $O$. stricta (Lotter and Hoffmann 1998). Cactoblastis cactorum Berg, a phycitid moth, was introduced into Australia and successfully controlled O. stricta (Dodd 1940), but was less successful in the KNP (Lotter and Hoffmann 1998; Hoffmann et al. 1998). It was also released in Kenya in 1971, but did not establish (Greathead 1971). As a result, the sap-sucking cochineal, Dactylopius opuntiae (Cockerell), originally introduced from Australia (ex Mexico) for the biological control of O. ficus-indica in South Africa, was also introduced on $O$. stricta in the KNP, but did not provide significant control either (Lotter and Hoffmann 1998). Opuntia stricta was deemed to be a sub-optimal host for this cochineal genotype. Another genotype of D. opuntiae, originally from Texas in the USA, was introduced to South Africa from Australia in 1997, where it had successfully controlled O. stricta and O. inermis (Dodd 1940; Hosking et al. 1994). This genotype showed a strong preference for O. stricta (Hoffmann et al. 1999; 
Volchansky et al. 1999). Its release in the KNP has resulted in a drop in the biomass of around $35 O$. stricta cladodes $/ \mathrm{m}^{2}$ to under 5 cladodes $/ \mathrm{m}^{2}$ (Paterson et al. 2011) and negated the need for physical and/or chemical control.

According to Winston et al. (2015), a genotype of the cochineal $D$. opuntiae which attacks $O$. ficusindica, was accidentally introduced into Kenya in the 1990s. It readily established in Laikipia County and significantly reduced the abundance of sweet prickly pear. Occasionally this cochineal will establish at very low densities on $O$. stricta where it has no impact whatsoever, as this cactus species is a sub-optimal host. In February 2014, after the initial release had been approved by the regulatory authorities, the genotype of $D$. opuntiae, which has effectively controlled O. stricta in South Africa, was released onto Ol Jogi Conservancy through a CABI initiative, in partnership with Ol Jogi, the local community and other agencies. The control agent has established well at OI Jogi and has started to spread from the initial release sites, reducing flowering, fruiting and in many cases has resulted in the death of plants. Permission to actively release this agent at other sites has been granted by the National Environment Authority and further introductions will be undertaken on communal lands.

\section{Conclusion}

A concerted effort is needed to mass-rear and release the genotype of D. opuntiae, introduced to Laikipia County for the control of $O$. stricta, in other invaded areas across eastern Africa. This will hopefully reduce the negative impacts on local livelihoods and the environment. Additional resources are required for research, to validate some of the findings of this study, and to monitor the effectiveness of the introduced biocontrol agent. It is also critical that management interventions, especially biocontrol, be developed and implemented for a large number of other invasive alien plant species in eastern Africa. Failure to address plant invasions will drive rural communities further into poverty with serious social and political ramifications.

Acknowledgements We thank Winnie Nunda for assisting with surveys and data entry; Corin Pratt for data entry and analysis; Tim Beale for developing the distribution maps; landowners for access to their land to undertake the surveys, for providing accommodation (especially John Weller and other O1 Jogi staff); and Laikipia community members who participated in the survey. Funding was also made available by the CABI Development Fund, which is supported by contributions from the Australian Centre for International Agricultural Research, Australia, the UK's Department for International Development, and others. Support for surveys and the production of distribution maps was provided by the GEF Small Grants Programme and JRS Biodiversity Foundation. We acknowledge support from the DST-NRF Centre of Excellence for Invasion Biology (C.I.B). During the writing of the paper ABRW was supported as a C.I.B Fellow. RTS acknowledges additional support from Stellenbosch University through "Consolidoc" funding through the office of the Vice Rector: Research, Innovation and Postgraduate Studies.

Open Access This article is distributed under the terms of the Creative Commons Attribution 4.0 International License (http:// creativecommons.org/licenses/by/4.0/), which permits unrestricted use, distribution, and reproduction in any medium, provided you give appropriate credit to the original author(s) and the source, provide a link to the Creative Commons license, and indicate if changes were made.

\section{References}

Barney RE (1925) Cactus spine pseudotubercule. Arch Derm Syphilol 11:331

Blackburn TM, Pyšek P, Bachner S, Carlton JT, Duncan RP, Jarošik V, Wilson JRU, Richardson DM (2011) A proposed unified framework for biological invasions. Trends Ecol Evol 26:333-339

Boyd W (1955) Pathology for the surgeon, 7th edn. W.B. Saunders Company, Philadelphia

Butyanski TM, de Jong YA (2015) Laikipia County: Geography, environment and biodiversity. Lolldaiga Hill Research programme and Sustainability Centre Eastern Africa, Nanyuki

CABI (2016) Opuntia stricta. In: Invasive species compendium. CAB International, Wallingford. www.cabi.org/isc. Accessed 20 Sept 2016

Chalmers N, Fabricius C (2007) Expert and generalist local knowledge about land-cover change in South Africa's Wild Coast: can local ecological knowledge add value to science? Ecol Soc 12:10

de Wit MP, Crookes DJ, van Wilgen BW (2001) Conflicts of interest in environmental management: estimating the costs and benefits of a tree invasion. Biol Invasions 3:167-178

Dean WRJ, Milton SJ (2000) Directed dispersal of Opuntia species in the Karoo, South Africa: are crows the responsible agents? J Arid Environ 45:305-314

Dodd AP (1940) The biological campaign against prickly pear. Commonwealth Prickly Pear Board, Brisbane, pp 1-177

Einkamerer OB, de Waal HO, Combrinck WJ, Fair MD (2009) Feed utilization and growth of Dorper wethers on Opuntiabased diets. S Afr J Anim Sci 39:53-57 
Foxcroft LC, Richardson DM (2003) Managing alien plant invasion in the Kruger National Park, South Africa. In: Child LE, Brock G, Brundu G, Prach K, Pyšek P, Wade PM, Williamson M (eds) Plant invasions: ecological threats and management solutions. Backhuys Publishers, Leiden, pp 385-404

Foxcroft LC, Rouget M, Richardson DM, MacFayden S (2004) Reconstructing 50 years of Opuntia stricta invasion in the Kruger National Park, South Africa: environmental determinants and propagule pressure. Divers Distrib 10:427-437

Foxcroft LC, Richardson DM, Wilson JRU (2008) Ornamental plants as invasive aliens: problems and solutions in Kruger National Park, South Africa. J Environ Manag 41:32-51

Garcia LG, Nicholson KL, Hoffman TW, Lawrence TE, Hale DS, Griffin DB, Savell JW, VanOverbeke DL, Morgan JB, Belk KE, Field TG, Scanga JA, Tatum JD, Smith GC (2008) National beef quality audit 2005; Survey of targeted cattle and carcass characteristics related to quality, quantity and value of fed steers and heifers. J Anim Sci $86: 3533-3543$

García-Llorente M, Martín-Lopes B, Nunes PALDJ, González A, Alcorlo P, Montes C (2011) Analyzing the social factors that influence willingness to pay for invasive species management under two different strategies: eradication and prevention. J Environ Manag 48:418-435

Government of Kenya (2013) First county development integrated development plan 2013-2017. Department of Finance, Planning and County Development, Laikipia County, Kenya

Greathead DJ (1971) A review of biological control in the Ethiopian region. Technical Communications No. 5, Commonwealth Institute of Biological Control, Commonwealth Agricultural Bureaux, Slough, pp 1-162

Hanselka CW, Paschal JC (1991) Pricklypear cactus: a Texas rangeland enigma. Rangelands 13:109-111

Henderson L (2007) Invasive, naturalised and casual alien plants in southern Africa: a summary based on the South African Plant Invaders Atlas (SAPIA). Bothalia 37:215-248

Hoffmann JH, Moran VC, Zeller DA (1998) Long-term population studies and the development of an integrated management programme for control of Opuntia stricta in Kruger National Park, South Africa. J Appl Ecol 35:156-160

Hoffmann JH, Moran VC, Zimmermann HG (1999) Integrated management of Opuntia stricta (Haworth) Haworth (Cactaceae) in South Africa: an enhanced role for two, renowned, insect agents. Afr Entomol Mem 1:14-20

Hosking JR, Sullivan PR, Welsby SM (1994) Biological control of Opuntia stricta (Haw.) Haw. var stricta using Dactylopius opuntiae (Cockerell) in an area of New South Wales, Australia, where Cactoblastis cactorum (Berg) is not a successful biological control agent. Agric Ecosyst Environ 48:241-255

Kannan R, Shackleton CM, Shaanker RU (2014) Invasive alien species as drivers in socio-ecological systems: local adaptions towards use of Lantana in southern India. Environ Dev Sustain 16:649-669

Kenya National Bureau of Statistics (2010) The 2009 Kenya population and housing census. Kenya National Bureau of Statistics, Nairobi
Kull CA, Shackleton CM, Cunningham PJ, Ducatillon C, Dufour-Dror J, Esler KJ, Friday JB, Gouveia AC, Griffin AR, Marchantem E, Midgley SJ, Pauchard A, Rangan H, Richardson DM, Rinaudo T, Tassin J, Urgenson LS, von Maltitz GP, Zenni RD, Zylstra MJ (2011) Adoption, use and perception of Australian acacias around the world. Divers Distrib 17:822-836

Larsson P (2004) Introduced Opuntia spp. in Southern Madagascar: problems and opportunities. SLU External Relations, Swedish University of Agricultural Sciences, Uppsala, Sweden

Lotter WD, Hoffmann JH (1998) An integrated management plan for the control of Opuntia stricta (Cactaceae) in the Kruger National Park, South Africa. Koedoe 41:63-68

Mack RN (2003) Global plant dispersal, naturalization, and invasion: pathways, modes and circumstances. In: Ruiz GM, Carlton JT (eds) Invasive species: vectors and management strategies. Island Press, Washington, pp 3-30

Merrill LB, Taylor CA, Dusek R, Livingston CW (1980) Sheep losses from range with heavy prickly pear infestation. In: Ueckert DN, Huston JE (eds) Rangeland resources research. Texas Agricultural Experiment Station Consol. Prog. Rep., 3665 pp

Moran VC, Hoffmann JH, Zimmermann HG (2005) Biological control of invasive alien plants in South Africa: necessity, circumspection and success. Front Ecol Environ 3:71-77

Novoa A, Le Roux JJ, Robertson MP, Wilson JRU, Richardson DM (2015) Introduced and invasive cactus species: a global review. Aob Plants. doi:10.1093/aobpla/plu078

Novoa A, Kaplan H, Wilson JRU, Richardson DM (2016) Resolving a prickly situation: involving stakeholders in invasive cactus management in South Africa. Environ Manag 57:998-1008

Nuñez MA, Pauchard A (2009) Biological invasions in developing and developed countries: does one model fit all? Biol Invasions 12:707-714

Page AR, Lacey KL (2006) Economic impact assessment for Australian weed biological control. CRC for Australian Weed Management, Australia

Parfitt BD, Gibson AC (2003) Cactaceae. In: Flora of North America Editorial Committee (ed) Flora of North America north of Mexico, vol 4. Oxford University Press, New York, pp 93-257

Paterson ID, Hoffmann JH, Klein H, Mathenge CW, Neser S, Zimmermann HG (2011) Biological control of Cactaceae in South Africa. Afr Entomol 19:230-246

Pimentel D (2002) Biological invasions: economic and environmental costs of alien plant, animal and microbe species. CRC, New York

Price DL, Heitschmidt RK, Dowhower SA, Frasure JR (1985) Rangeland vegetation response following control of brownspine pricklypear (Opuntia phaecantha) with herbicides. Weed Sci 33:640-643

Rejmánek M, Richardson DM (2013) Trees and shrubs and invasive alien species - 2013 update of the global database. Divers Distrib 19:1093-1094

Rejmánek M, Le Roux JJ, Huntley BJ, Richardson DM (2016) Rapid assessment survey of the invasive plant species in western Angola. Afr J Ecol. doi:10.1111/aje.12315 
Richardson DM, Rejmánek M (2011) Trees and shrubs as invasive alien species-a global review. Divers Distrib 17:788-809

Schreiber MM, Shapiro SI, Berry CZ (1971) Cactus granulomas of the skin. Arch Dermatol 104(4):374-379

Shackleton CM, McGarry D, Fourie S, Gambiza J, Shackleton SE, Fabricius C (2007) Assessing the effect of invasive alien species on rural livelihoods: case examples and a framework from South Africa. Hum Ecol 35:113-127

Shackleton S, Kirby D, Gambiz J (2011) Invasive plantsfriends or foes? Contribution of prickly pear (Opuntia ficus-indica) to livelihoods in the Makana Municipality, Eastern Cape, South Africa. Dev South Afr 28:177-193

Shackleton RT, Le Maitre DC, Pasiecznik NM, Richardson DM (2014) Prosopis: a global assessment of the biogeography, benefits, impacts and management of one of the world's worst woody invasive plant taxa. AoB Plants 6:plu027. doi:10.1093/aobpla/plu027

Shackleton RT, Le Maitre DC, Richardson DM (2015) Stakeholder perceptions and practices regarding Prosopis (mesquite) invasions and management in South Africa. Ambio 44:569-581

Simberloff D, Martin JL, Genovesi P, Maris V, Wardle DA, Aronson J, Courchamp F, Galil B, García-Berthou E, Pascal M, Pyšek P, Sousa R, Tabacchi E, Vilá M (2013) Impacts of biological invasions. What's what and the way forward. Trends Ecol Evol 28:58-66

Smit C, Béguin D, Buttler A, Mueller-Schaerer H (2005) Safe sites for tree regeneration in wooded pastures: a case of associational resistance? J Veg Sci 16:209-214

Smit C, den Ouden J, Mueller-Schaerer H (2006) Unpalatable plants facilitate tree sapling survival in wooded pastures. J Appl Ecol 43:305-312

Smit C, Vandenberghe C, den Ouden J, Müller-Schärer H (2007) Nurse plants, tree saplings and grazing pressure: changes in facilitation along a biotic environmental gradient. Oecologia 152(2):265-273

Strum SC, Stirling G, Kulusi Mutunga SK (2015) The perfect storm: land use change promotes Opuntia stricta's invasion of pastoral rangelands in Kenya. J Arid Environ 118:37-47

Sundaram B, Krishnan S, Hiremath AJ, Joseph G (2012) Ecology and impacts of the invasive species, Lantana camara, in a social-ecological system in south India: perspectives from local knowledge. Hum Ecol 40:931-942

Tangka FK, Jabbar MA, Shapiro BI (2000) Gender roles and child nutrition in livestock production systems in developing countries: a critical review. Socio-economics and Policy Research Working Paper 27 (ILRI) International Livestock Research Institute: Nairobi, Kenya

Taylor WR, Whitson TD (1999) Plains prickly pear cactus control. University of Wyoming, Cooperative Extension Service, Bulletin No. B-1074

Ueckert DN, Livingston Jr CW, Huston JE, Menzies CS, Dusek RK, Petersen JD, Lawrence BK (1990) Range and sheep management for reducing pear-moth and other prickly pear-related health problems in sheep flock. Sheep and Goat, Wool and Mohair, Research Report. Texas Agricultural Experiment Station. San Angelo, Texas, USA

van Wilgen BW, Richardson DM (2014) Challenges and tradeoffs in the management of invasive alien trees. Biol Invasions 16:721-734

van Wilgen BW, Forsyth GG, Le Maitre DC, Wannenburgh A, Kotze DF, van den Berg E, Henderson L (2012) An assessment of the effectiveness of a large, national-scale invasive alien plant control strategy in South Africa. Biol Conserv 148:28-38

Vilá M, Gimeno I (2003) Seed predation of two alien Opuntia species invading Mediterranean communities. Plant Ecol 167:1-8

Vilá M, Burriel JA, Pino J, Chamizo J, Llach E, Porterias M, Vives M (2003) Association between Opuntia species invasion and changes in land-cover in the Mediterranean region. Glob Change Biol 9:1234-1239

Volchansky CR, Hoffmann JH, Zimmermann HG (1999) Hostplant affinities of two biotypes of Dactylopius opuntiae (Homoptera: Dactylopiidae): enhanced prospect for biological control of $O$. stricta (Cactaceae) in South Africa. J Appl Ecol 36:85-91

Winston RL, Shwarzländer M, Hinz HL, Day MD, Cock MJW, Julien MH (eds) (2015) Biological control of weeds: a world catalogue of agents and their target weeds, 5th edn. USDA Forest Service, Forest Health Technology Enterprise Team, Morgantown, West Virginia. FHTET-201404, pp 1-838 